\title{
From a Success Index to a Success Multiplier
}

Ronald Rousseau and Sandra Rousseau

\section{Introduction: The Success Index}

Recently Kosmulski (2011) and Franceschini et al. (2012a) introduced the success index. This indicator, or better, family of indicators, is constructed as follows. One considers a set of articles and collects for each of these the number of citations received over a given citation window W. In a first step, a binary score (zero or one) is determined for each of these articles: the score is one if the citations received by a particular article reach a certain threshold value and it is zero otherwise. This threshold can be determined in a variety of ways (which is why we say that the success index is actually a family of indicators). In a next step the success index of this set of articles with respect to a particular threshold is defined as the number of publications that has reached the threshold, or stated otherwise: the sum of all binary scores. Some variations of this index can be considered in which, for instance, time plays a role (Kosmulski, 2011). Among other proposals, the following thresholds could be used (Kosmulski, 2011; Franceschini et al., 2012a, b):

a.) The number of references (each publication's citations is compared with its own number of references). This is the original proposal by Kosmulski (2011).

b.) The mean or the median number of references in articles published in the same journal and year as the article under consideration.

c) The mean or the median number of citations received by articles published in the same journal and year as the article under consideration, where citations are gathered over the same period W (Franceschini et al., 2012a,b). Kosmulski referred to this proposal as a modesty index, as it would reward publication of high-impact articles in lower impact journals (Kosmulski, 2012).

We note that, in general, an index can be defined as a number, derived from a formula, characterizing a property of a dataset. As such, this index is an indicator for a particular characteristic. In the case of a success index, the set of data is a set of articles and their citations, and its value is used as a proxy for the 'success' - the term visibility or popularity would be more to the point - of this dataset and the corresponding entity (scientist, department, journal). In this contribution we provide a short review of the family of success indices and introduce the success multiplier, a non-discrete version of the success index. The success multiplier is a number indicating to which extent citations reached or exceeded a threshold value. Examples are provided for articles published in the Journal of the American 
Society for Information Science and Technology, volumes 53 and 54 in 2002 and 2003. A simple statistical prediction exercise is performed for three success indices and the corresponding multipliers. Results are described as a function of variables such as the highest h-index of contributing authors, gender of the authors, content descriptors, and affiliation.

\section{Overview of Relevant Indicators}

In this section we provide an overview of several relevant indicator groups. First we look at the success index family, next we consider payback times and the success multiplier. Finally, we discuss some mathematical properties of these indicators.

\section{The Success Index Family}

Besides the three thresholds mentioned in the introduction, Franceschini et al. (2012a, b) also consider the following thresholds:

- The mean or the median number of references in articles belonging to a neighborhood of the article under consideration.

- The mean or the median number of citations received by articles belonging to a neighborhood of the article under consideration, where citations are gathered over the same period $\mathrm{W}$.

In these cases there are many ways of defining a neighborhood of a given article. Consider the (directed) citation ego network of a given article A (Hu et al., 2011) and define a neighborhood of $\mathrm{A}$ as all articles at distance at most one, at most two,... in the cited direction (or in the citing direction), or neglecting the direction.

Clearly, the amount of possible thresholds is limitless. One may, for instance, define a threshold by only considering citations in journals belonging to the first quartile in one of Thomson Reuters' JCR categories, or citations received from authors with a high h-index. Such approaches would operationalize the idea of "quality citations". Alternatively, one may consider only recent references.

In the examples presented thus far, we only considered received citations (or stated otherwise: different citing articles). Yet, instead of different citing articles, one can compute different citers (authors, journals, countries, etc.). In such cases the threshold must also be adapted as explained in Franceschini et al. (2014), where the problem is studied and examples are provided for citing authors.

Besides absolute success indices, one can also consider relative success indices of a set, defined as the success index of this set divided by the number of publications in the set 
under study. Finally, if all articles in a set are gauged with respect to the same threshold such as the average number of citations of the journal in which they are published (assuming that all articles in the set are all published in the same year and in the same journal), one may define the success index of a set of articles by comparing received citations and $\mathrm{n}$ (the number of articles in the set) times this threshold value. The result is again a success index which is either equal to one or to zero. Of course, this approach is not always meaningful, for instance if the set consists of all articles published in a given journal and year and the threshold is determined as its average number of citations. The success index has been studied in a Lotkaian framework by Egghe (2014), and further clarified by Rousseau (2014a).

Payback Times: A Variation on the Success Index

Instead of determining whether a given article has reached a certain threshold, a more dynamic approach can be considered by determining how long it takes for an article to reach the threshold. Actually, this idea precedes the concept of a success index. It was proposed by Liang and Rousseau (2008) for journals and is referred to as the yield period or the payback time. The phrase 'payback time' refers to the idea that a journal uses resources from the science system (as shown by its list of references) and that it takes a certain time to pay back (through received citations) to the science system what had been taken. Liang and Rousseau (2008) studied yearly issues of Science and Nature, leading to so-called yield sequences. They determined not only the time to reach a number of citations equal to the number of used references, but also the time to reach twice, thrice, ... this number. It was observed that payback times tended to become shorter over the years. Another variation on the success index and the idea of a payback time would be to consider the percentage of articles in a given set that already reached the threshold after a given time t.

\section{The Success Multiplier}

Instead of a binary score leading to a success index, we can also determine the fraction of the threshold reached by an article at any given moment. For instance, if the threshold is 10 citations and an article has obtained 7 citations, a value 0.7 can be associated with it.

Similarly, if an article received 15 citations, it receives a value of 1.5 . The values 0.7 and 1.5 are then referred to as multipliers. An article's multiplier reflects the relative number of citations received by that article compared to the threshold value that is used.

The success multiplier of a set of articles is simply the sum of the scores of all articles in the set, generalizing the success index of a set of articles. When using success multipliers it is still possible to separate an elite set from the other ones, but this division is not as clear-cut as in the $0-1$ case. Further, an average score is created by dividing this general score by the 
total number of articles. When the number of references is used as a threshold this leads to the formula

$$
\text { 1.) } \frac{1}{n} \sum_{j=1}^{n} \frac{c_{j}}{r_{j}}
$$

Here $\mathrm{n}$ is the number of publications under consideration, $\mathrm{c}_{\mathrm{j}}$ is the number of citations received by article $j$ (over a given citation window) and $r_{j}$ is the number of references of article j. In case all articles' citations are compared with the same threshold, say T, then formula (1) becomes:

$$
\text { 2.) } \frac{1}{n * T} \sum_{j=1}^{n} c_{j}
$$

This average score no longer has a theoretical upper limit. Note that the multiplier idea is not completely new. Yanovsky (1981) was likely the first to use a ratio of citations over references as a bibliometric indicator (his popularity factor and citation factor). Multipliers have also been proposed for scientific leadership by Matsas (2012) under the name of Normalized Impact Factor (NIF). The NIF of scientist A in the sense of Matsas is defined as:

$$
\text { 3.) } \operatorname{NIF}(A)=\frac{\sum_{j=1}^{n} a_{j} c_{j}}{\sum_{j=1}^{n} b_{j} r_{j}}=\frac{\left(\sum_{j=1}^{n} a_{j} c_{j}\right) / n}{\left(\sum_{j=1}^{n} b_{j} r_{j}\right) / n}
$$

Here $\mathrm{n}$ is the number of publications written by scientist $\mathrm{A}$, during a given period; $\mathrm{c}_{\mathrm{j}}$ is the number of citations received by article $j$ (again over a given citation window) and $r_{j}$ is the number of references of article $j$. The numbers $a_{j}$ and $b_{j}$ are weighting factors. In the simplest case they are all equal to one. In a somewhat more complex setup, one may take $a_{j}=b_{j}=$ $1 /$ (the number of authors of article $\mathrm{j}$ ); of course many other weighting factors are feasible. NIF(A) is the weighted average number of received citations divided by the weighted average number of references. Note that here we run across the well-known difference between ratios of averages and averages of ratios (Larivière \& Gingras, 2011). In formula (1) we proposed an average of ratios (when dividing by the total number of articles in the set) while Matsas, formula (3), proposed a (weighted) ratio of averages.

Matsas' Normalized Impact Factor is very similar to the Reference Return Ratio (3R in short) for journals introduced by Nicolaisen and Frandsen (2008). This indicator for journal $\mathrm{J}$ is defined as:

$$
3 R(J)=\frac{\sum_{j=1}^{n} c_{j}}{\sum_{j=1}^{n} r_{j}}
$$


where the numerator denotes the number of citations received during a given citation window by articles published during a given publication window (in the journal under consideration) and the denominator denotes the total number of references in those same articles (published during the publication window), where only references published during a given reference window are taken into account.

Besides using direct citations, one may also consider second-generation or higher forward generation effects (recall that second and higher generations may be defined in different ways as explained in $\mathrm{Hu}$ et al. [2011]) and calculate the multiplier for the first, second, or higher generation only.

\section{Mathematical Properties}

Bouyssou and Marchant (2011) represent an author by a mapping f from the natural numbers to the natural numbers, where $\mathrm{f}(\mathrm{x})$ denotes the number of articles with exactly $\mathrm{x}$ citations, i.e., the frequency distribution of citations over articles in the author's publication set. We observe that in their discussion an author is actually represented by the set of his/her publications and hence the analysis in Bouyssou and Marchant (2011) applies to any set of articles.

We note that a success index is independent according to the terminology used by Bouyssou and Marchant. This means that if the value for set $S_{1}$ is larger than or equal to the value for set $S_{2}$, and one adds a publication with the same number of citations to each set, leading to sets $\mathrm{S}_{1}$ ' and $\mathrm{S}_{2}$ ' then the value of this success index for $\mathrm{S}_{1}$ ' is larger than or equal to that for $\mathrm{S}_{2}$ '. Note that if the threshold value is determined by some external set (such as the median value of all articles in the same journal as those of the set $S$ ) then this threshold value must be the same for sets $S_{1}$ and $S_{2}$ for the previously mentioned property to hold. This property, though seemingly obvious, is not satisfied by the h-index. Clearly, success multipliers are also independent in this sense.

Moreover, Franceschini et al. (2014) showed that the union of two disjoint groups of publications with success indices $\mathrm{su}^{(1)}$ and $\mathrm{su}^{(2)}$ has success index $\mathrm{su}^{(1)}+\mathrm{su}^{(2)}$ (with the same restriction for the thresholds). Again this addition property remains valid for success multipliers.

Clearly these properties are not satisfied by relative success indices or by relative success multipliers. Indeed, if set $S_{1}$ contains 3 articles of which 2 have reached the threshold value and set $S_{2}$ contains 30 articles of which 21 have reached the threshold value then the relative success index for $S_{1}$ is $2 / 3$ which is smaller than the $21 / 30$, the relative success index of $\mathrm{S}_{2}$. Adding one publication that has reached the threshold to both sets, we obtain the new relative values $3 / 4=0.75$ and $22 / 31 \approx 0.71$. As a result the relative success index of set $\mathrm{S}_{1}$ 
becomes larger than that of $\mathrm{S}_{2}$, contradicting the independence requirement. Yet, if $\mathrm{S}_{1}$ and $\mathrm{S}_{2}$ contain the same number of elements, the independence requirement is clearly satisfied.

Observing that, for instance $\frac{2}{7}+\frac{3}{7} \neq \frac{5}{14}$, suffices to show that also the addition property is not satisfied for relative success indices even if sets have the same number of elements. Considering now the case of success multipliers, we immediately assume that $S_{1}$ and $S_{2}$ have the same number of elements. It is clear that, using formula (1), if

$$
\frac{1}{n} \sum_{j=1}^{n} \frac{c_{j}}{r_{j}} \leq \frac{1}{n} \sum_{j=1}^{n} \frac{c_{j}^{\prime}}{r_{j}^{\prime}} \text { then also } \frac{1}{n+1}\left(\sum_{j=1}^{n} \frac{c_{j}}{r_{j}}+\frac{c_{n+1}}{r_{n+1}}\right) \leq \frac{1}{n+1}\left(\sum_{j=1}^{n} \frac{c_{j}^{\prime}}{r_{j}^{\prime}}+\frac{c_{n+1}}{r_{n+1}}\right)
$$

This property also holds when using formula (2). Yet, the property does not hold for formula (3), taking all weights equal to 1 for simplicity. Indeed: $\frac{5+4}{10+10} \leq \frac{1+2}{3+3}$ but, adding one article with zero citations and two references yields: $\frac{5+4+0}{10+10+2}>\frac{1+2+0}{3+3+2}$. Finally, as the addition property is not satisfied for relative success indices, it is certainly not satisfied for relative success multipliers.

\section{An Empirical Illustration}

Next, we collected a dataset in order to have a closer look at success indices and success multipliers in practice. More specifically, we consider all publications in the Journal of the American Society for Information Science and Technology (JASIST) in the years 2002 and 2003. This set is restricted to those publications classified as articles in the Web of Science (WoS). The dataset contained 208 articles. Data collection took place during the first week of June 2014.

After defining and describing three success indices and three corresponding success multipliers, we performed a statistical analysis to identify factors that can be used to predict the different success indicators.

\section{Examples: Success Indices}

Three success indices for the articles in our dataset are determined by using three different thresholds. These indices are denoted by $\mathrm{SU}_{1}, \mathrm{SU}_{2}$ and $\mathrm{SU}_{3}$, and defined as:

$$
\begin{gathered}
\mathrm{SU}_{1}=1 \text { if number of received citations } \geq \text { number of references used, } \\
\mathrm{SU}_{2}=1 \text { if number of received citations } \geq \text { average number of references used in year of } \\
\text { publication (in articles in JASIST), and }
\end{gathered}
$$


$\mathrm{SU}_{3}=1$ if number of received citations $\geq$ average number of citations received by

JASIST articles in the year of publication.

The average number of references and the average number of citations for our dataset is presented in Table 1. Articles published in 2002 were cited more frequently on average than articles published in 2003, while their average number of references was lower.

(Table 1 here)

We note that the indices $\mathrm{SU}_{1}$ and $\mathrm{SU}_{2}$ (corresponding to thresholds a and $\mathrm{b}$ of the introduction) have a static denominator and hence are non-decreasing, while the third one $\mathrm{SU}_{3}$ (comparing with the average number of received citations) has a dynamic denominator if the citation window extends to the date of data collection. Hence the resulting index may fluctuate depending on the fact if the target publication receives citations faster or slower than the average of the set of publications under consideration.

The calculated values for the three indices are distributed as shown in Table 2. Clearly comparing the number of citations to an article to an article's own reference list and comparing to the average number of received citations yield very similar results, while comparing the number of citations to the average number of references makes it somewhat more difficult to be a successful article. Recall that these are citation values obtained after more than ten years (i.e., in June 2014).

(Table 2 here)

It is not because the percentages of successful articles for $\mathrm{SU}_{1}$ and $\mathrm{SU}_{3}$ are almost the same that these percentages necessarily refer to the same articles. We check this in Table 3. For most articles the values for $\mathrm{SU}_{1}$ and $\mathrm{SU}_{3}$ are identical. Still, for some 15 percent of the articles in this dataset the results for both indices differ.

(Table 3 here)

In addition, we note that the percentage of articles for which $\mathrm{SU}_{3}=1$ is smaller than 0.5 (namely 0.317 ) as expected by the well-known skewness of citation distributions (Rousseau, 2014b). Figure 1 shows the citation distribution. Its skewness coefficient is 1.98; $44.23 \%$ of the articles received between 0 and 10 (incl.) citations over a period of more than ten years.

(Figure 1 here)

\section{Examples: Multipliers}

Next, we calculated the multiplier values for the same articles. These are denoted MULTI $\mathrm{MULTI}_{2}$ and $\mathrm{MULTI}_{3}$ and defined as:

$\operatorname{MULTI}_{1}=$ number of received citations / number of references used, 
$\mathrm{MULTI}_{2}=$ number of received citations / average number of references used in year of publication (in articles in JASIST), and

$\mathrm{MULTI}_{3}=$ number of received citations / average number of citations received by JASIST articles in the year of publication.

The distributions of these three multipliers are shown in Figures 2, 3 and 4.

(Figures 2, 3, 4 here)

The five articles with the highest values for MULTI $1, \mathrm{MULTI}_{2}, \mathrm{MULTI}_{3}$ and number of received citations are shown in Tables 4 and 5. Note that, by definition, ranks according to $\mathrm{MULTI}_{2}, \mathrm{MULTI}_{3}$ and total number of received citations are the same. Coincidentally, there are more articles published in 2003 in these lists than articles published in 2002.

(Tables 4, 5 here)

\section{A Statistical Approach}

As a small exercise we try to predict (certainly not explain) $\mathrm{SU}_{1}, \mathrm{SU}_{2}, \mathrm{SU}_{3}, \mathrm{MULTI}_{1}$, $\mathrm{MULTI}_{2}, \mathrm{MULTI}_{3}$ and the total number of received citations (TC) as a function of some predicting variables. For the continuous variables $\mathrm{MULTI}_{1}, \mathrm{MULTI}_{2}, \mathrm{MULTI}_{3}$ and total citations (TC), we used OLS (ordinary least squares), while for the discrete cases, $\mathrm{SU}_{1}, \mathrm{SU}_{2}$, $\mathrm{SU}_{3}$, we used a logistic regression. From the literature (Deschacht \& Engels, 2014; Didegah, 2014; Didegah \& Thelwall, 2013) we know that possible predictors, at least for TC (we mention TC because, to the best of our knowledge, a regression analysis has never been performed for the success index) include: the journal's impact factor, the h-index of the authors, whether authors come from an English speaking country or not, the number of coauthors, the number of references, the number of countries in the address byline, the number of institutions involved in the research, the size of the field, the recency of references, the field, the specific topic, the type of document, the number of female authors, the length of the article, the length of the title, the readability of the article, etc.

Some of these factors clearly do not apply to the present situation such as the field, the journal's impact factor (all articles are published in JASIST), or the type of document (we only use the article type). Other factors were not constructed and therefore not applied, such as the recency of references or the readability of the article. Moreover, some factors were dichotomized such as number of authors (one or more), number of female authors (one or more), while others were somewhat adapted (see further). The gender of authors was determined manually by searching for pictures on the Internet (at least in those cases where we did not know the author(s) personally). Finally we tried a few factors which may not have been studied before. The list of predictors is provided in Table 6 . 
(Table 6 here)

Of course, some of the listed variables were never applied together, such as a variable and its dichotomized version. Furthermore, it turned out that some of these possible predictors were never significant or were not significant in combination with other highly significant ones.

We were not able to determine the gender of a few authors in the dataset. The corresponding six articles were thus removed from the analysis and the final analysis was done for 202 (or 201) articles. Indeed, it was not possible to calculate MULTI for one article as it had no references, leading to 201 articles in the case where a division by the number of actual references had to be performed.

Finally the following variables were at least once statistically significant on the $10 \%$ level: Hirschmax, Pages, Female, Keynr, Web, Retrieval, Y2002, Tec, and Dauthors. Results of our econometric estimation, performed in STATA, are presented in Table 7. For the OLS the adjusted $\mathrm{R}^{2}$ is given, while for the logistic regression the pseudo $\mathrm{R}^{2}$ is shown.

(Table 7 here)

\section{Discussion of the Regression Results}

The majority of the results were expected; however, several require some more discussion. The fact that the highest h-index of the co-authors is usually highly significant is not surprising and might be related to the Matthew Effect (see also Egghe et al., 2013; Glänzel and Schubert, this volume). A perhaps surprising result is the positive influence of the number of keywords. As JASIST did not have author keywords at that time, only KeyWords Plus are used. These are automatically generated by Thomson Reuters based on frequently occurring terms and phrases in the reference list. Still, the fact that these keywords are related - via references - to the content of the articles and are used for queries in the Web of Science seems to have its rewards, resulting in higher values for success indicators. The fact that a higher number of authors has no influence (or occasionally a negative one) is also not obvious. This result might be explained by the correlation between the number of authors and the number of female authors (Pearson correlation of 0.36). For this reason, we removed number of authors (but kept Dauthors). Still, having more than one author seems to influence the probability of being successful based on the $\mathrm{SU}_{3}$-index negatively. In addition, there is some weak evidence that a longer article (more published pages) leads to more success as expressed by the $\mathrm{SU}_{3}$-index. Moreover, one would expect that after more than ten years one

year more of exposure would not have any influence on the success indicators, but see Table 1. While the variable Y2002 does not influence the success multipliers, it does make a difference with respect to the number of received citations and hence with respect to the 
success indices $\mathrm{SU}_{1}$ and $\mathrm{SU}_{2}$. Further, we find that topics and type of institute are of importance (at least for these data); technical institutes have a positive influence as do web discussions, while retrieval-related articles are less successful. Finally, female colleagues have a positive influence on the number of citations and hence on the success (however measured) of these articles. This observation differs from that made in earlier work (Cronin, 1996; Larivière et al., 2013). Yet, as we only studied one journal in the social sciences and a short publication period, this is, of course, no contradiction. Let us consider it an encouraging sign for female scientists.

\section{Conclusion}

The success index and its extension to rational numbers, the success multiplier, form a versatile family of research indicators. Some versions, such as $\mathrm{SU}_{1}$, are not suitable for research evaluation as they are too easy to manipulate. Yet, the more difficult to manipulate (when comparing with a representative median number of citations, it becomes much more difficult to influence the result), the higher their potential in informetric studies. Our contribution provides only a small example (JASIST, volumes 53 - 54) of their use and thus more examples leading to a better appreciation of their advantages and disadvantages are required.

We note that some of the thresholds lead to an input-output system, thus the corresponding indicator can be considered an input-output indicator. Clearly, cases a and b, where the threshold is determined by references, fall within the input-output framework, while case $\mathrm{c}$, for which the threshold is determined by citations received by related articles, does not. Related indicators such as Matsas' NIF and the 3R-indicator also are input-output indicators.

These input-output indicators treat articles as devices that create citations by using a certain amount of inputs (i.e., references). Such indicators, if applied in evaluation exercises would lead to a market-based strategy by which publication/citation maximization brings game players significant economic gains (Cronin, 1996). As such, input-output indicators reinforce the current culture of assessing academic success in terms of publications and citations, rather than stimulating original research as valuable in its own right. Success indices should hence be used to describe a current state and not to evaluate research or researchers. Furthermore, input-output indicators that are defined as ratios are not useful to help with decision making. Success multipliers rely on averages and as such tell an author nothing about the value of adding one more reference to a manuscript. Multipliers could 
provide a useful picture of the degree of internal linkage which exists in publication - citation networks.

Acknowledgments. The authors thank Cassidy Sugimoto and Domenico Maisano for helpful suggestions.

\section{Cited References}

Bouyssou, D., \& Marchant, T. (2011). Ranking scientists and departments in a consistent manner. Journal of the American Society for Information Science and Technology, 62(9), 1761-1769.

Cronin, B. (1996). Rates of return to citation. Journal of Documentation, 52(2), 188-197.

Deschacht, N., \& Engels, T.C.E. (2014). Limited dependent variable models and probabilistic prediction in informetrics. In Y. Ding, R. Rousseau, \& D. Wolfram (Eds.) Measuring Scholarly Impact: Methods and Practice. Springer, p. 193-214.

Didegah, F. (2014). Factors associating with the future citation impact of published articles: a statistical modelling approach. Doctoral dissertation. University of Wolverhampton.

Didegah, F., \& Thelwall, M. (2013). Determinants of research citation impact in nanoscience and nanotechnology. Journal of the American Society for Information Science and Technology, 64(55), 1055-1064.

Egghe, L. (2014). Impact coverage of the success-index. Journal of Informetrics, 8(2), 384389.

Egghe, L., Guns, R., \& Rousseau, R. (2013). Measuring co-authors' contribution to an article's visibility. Scientometrics, 95(1), 55-67.

Franceschini, F., Galetto, M., Maisano, D., \& Mastrogiacomo, L. (2012a). The successindex: an alternative approach to the h-index for evaluating an individual's research output. Scientometrics, 92(3), 621-641.

Franceschini, F., Galetto, M., Maisano, D., \& Mastrogiacomo, L. (2012b). Further clarifications about the success-index. Journal of Informetrics, 6(4), 669-673.

Franceschini, F., Maisano, D., \& Mastrogiacomo, L. (2014). The citer-success-index: a citerbased indicator to select a subset of elite papers. Scientometrics, 101(2), 963-983.

Hu, XJ., Rousseau, R., \& Chen, J. (2011). On the definition of forward and backward citation generations. Journal of Informetrics, 5(1), 27-36.

Kosmulski, M. (2011). Successful papers: a new idea in evaluation of scientific output. 
Journal of Informetrics, 5(3), 481-485.

Kosmulski. M. (2012). Modesty-index. Journal of Informetrics, 6(3), 368-369.

Larivière, V. \& Gingras, Y. (2011). Averages of ratios vs. ratios of averages: an empirical analysis of four levels of aggregation. Journal of Informetrics, 5(3), 392-399.

Larivière, V., Ni, CQ., Gingras, Y., Cronin, B., \& Sugimoto, C.R. (2013). Global gender disparities in science. Nature, 504(7479), 211-213.

Liang, LM., \& Rousseau, R. (2008). Yield sequences as journal attractivity indicators: payback times for Science and Nature. Journal of Documentation, 64(2), 229-245.

Matsas, G.E.A. (2012). What are scientific leaders? The introduction of a normalized impact factor. Brazilian Journal of Physics, 42(5-6), 319-322.

Nicolaisen, J. \& Frandsen, T.F. (2008). The reference return ratio. Journal of Informetrics, 2(2), 128-135.

Rousseau, R. (2014a). Comments on "Impact coverage of the success-index" by Leo Egghe. Journal of Informetrics, 8(3), 491- 492.

Rousseau, R. (2014b). Skewness for citation curves. In E. Noyons (Ed.). Context Counts: Pathways to Master Big and Little Data. Proceedings of STI 2014, Leiden, Universiteit Leiden, p. 498-501.

Yanovsky, V.I. (1981). Citation analysis significance of scientific journals. Scientometrics, 3(3), 223-233. 
Table 1: Average number of references and citations per year

\begin{tabular}{|c|c|c|}
\hline & $\begin{array}{c}\text { Average number of } \\
\text { references }\end{array}$ & $\begin{array}{c}\text { Average number of } \\
\text { citations }\end{array}$ \\
\hline 2002 & 32.31 & 27.09 \\
2003 & 34.35 & 22.71 \\
\hline
\end{tabular}

Table 2: Percentages of successful JASIST articles, according to three success indices

\begin{tabular}{|l|c|c|}
\hline & No success & Success \\
\hline $\mathrm{SU}_{1}$ & $68.1 \%$ & $31.9 \%$ \\
$\mathrm{SU}_{2}$ & $74.0 \%$ & $26.0 \%$ \\
$\mathrm{SU}_{3}$ & $68.3 \%$ & $31.7 \%$ \\
\hline
\end{tabular}

Table 3: Overlap between $\mathrm{SU}_{1}$ and $\mathrm{SU}_{3}$

\begin{tabular}{|c|c|c|c|}
\hline & $\mathrm{SU}_{3}=0$ & $\mathrm{SU}_{3}=1$ & Total \\
\hline $\mathrm{SU}_{1}=0$ & 125 & 16 & 141 \\
$\mathrm{SU}_{1}=1$ & 16 & 51 & 67 \\
\hline Total & 141 & 67 & 208 \\
\hline
\end{tabular}

Table 4: The five articles with the highest MULTI ${ }_{1}$ values

\begin{tabular}{|l|l|c|l|l|c|}
\hline Rank & Author(s) & \# references & $\begin{array}{l}\text { Volume - issue - } \\
\text { year }\end{array}$ & Pages & $\begin{array}{c}\text { MULTI } \\
\text { value }\end{array}$ \\
\hline 1 & $\begin{array}{l}\text { Pudovkin, AI; Garfield, } \\
\text { E }\end{array}$ & 15 & $53-13-2002$ & $1113-1119$ & 6.0 \\
\hline & $\begin{array}{l}\text { Garfield, E; Pudovkin, } \\
\text { AI; Istomin, VS }\end{array}$ & 7 & $54-5-2003$ & $400-412$ & 6.0 \\
\hline 3 & $\begin{array}{l}\text { Ahlgren, P; Jarneving, } \\
\text { B; Rousseau, R }\end{array}$ & 35 & $54-6-2003$ & $550-560$ & 4.31 \\
\hline 4 & $\begin{array}{l}\text { Morris, SA; Yen, G; } \\
\text { Wu, Z; Asnake, B }\end{array}$ & 15 & $54-5-2003$ & $413-422$ & 3.67 \\
\hline 5 & White, HD & 20 & $54-13-2003$ & $1250-1259$ & 3.5 \\
\hline
\end{tabular}

Table 5: The five articles with the highest numbers of received citations, $\mathrm{MULTI}_{2}$ and $\mathrm{MULTI}_{3}$ values

\begin{tabular}{|l|l|l|l|c|c|c|}
\hline Rank & Author(s) & $\begin{array}{l}\text { Volume - issue - } \\
\text { year }\end{array}$ & Pages & $\begin{array}{c}\text { \# received } \\
\text { citations }\end{array}$ & $\begin{array}{c}\text { MULTI } \\
\text { value }\end{array}$ & $\begin{array}{c}\text { MULTI } \\
\text { value }\end{array}$ \\
\hline 1 & $\begin{array}{l}\text { Ahlgren, P; } \\
\text { Jarneving, B; } \\
\text { Rousseau, R }\end{array}$ & $54-6-2003$ & $550-560$ & 151 & 6.06 & 4.53 \\
\hline 2 & Rieh, SY & $53-2-2002$ & $145-161$ & 148 & 5.94 & 4.44 \\
\hline 3 & $\begin{array}{l}\text { Wathen, CN; } \\
\text { Burkell, J }\end{array}$ & $53-2-2002$ & $134-144$ & 126 & 5.06 & 3.78 \\
\hline 4 & Borlund, P & $54-10-2003$ & $913-925$ & 125 & 5.02 & 3.75 \\
\hline 5 & White, HD & $54-13-2003$ & $1250-1259$ & 108 & 4.33 & 3.24 \\
\hline
\end{tabular}


Table 6: List of possible predictors

\begin{tabular}{|c|c|}
\hline Variable name & Definition \\
\hline MINREF & $=1$, if the number of references is less than 15 \\
\hline MAXREF & $=1$ if the number of references is 50 or more \\
\hline Y2002 & $=1$ if the article has published in 2002 \\
\hline COUNTAUTHORS & Number of co-authors \\
\hline DAUTHORS & $=1$ if the article was written by more than 1 author \\
\hline FEMALE & Number of female authors \\
\hline DFEMALE & $=1$ if at least one author is female \\
\hline PAGES & Length of article expressed as number of pages \\
\hline USA & $=1$ if at least one of the affiliations is in the USA \\
\hline ASIA & $=1$ if at least one of the affiliations is in Asia (excl. Israel) \\
\hline TEC & $=1$ if at least one the affiliations has the letters 'tec' in its name \\
\hline COMP & $=1$ if at least one of the affiliations has the letters 'comp' in its name \\
\hline KEYNR & Number of keywords \\
\hline RETRIEVAL & $=1$ if at least one of the keywords contains the word 'retrieval' \\
\hline WEB & $\begin{array}{l}=1 \text { if at least one of the keywords contains one of the words 'www', } \\
\text { 'internet', 'online' or 'world wide web' }\end{array}$ \\
\hline HIRSCHMAX & $\begin{array}{l}\text { The maximum h-index among all co-authors on January 1, } 2003 \text { according } \\
\text { to the WoS }\end{array}$ \\
\hline TIME & Time in days between date of acceptance and date of submission \\
\hline
\end{tabular}

Table 7: Summary of obtained results

\begin{tabular}{|c|c|c|c|c|c|c|c|}
\hline \multirow[t]{2}{*}{ predictors } & \multicolumn{3}{|c|}{ Multipliers } & \multicolumn{3}{|c|}{ Success indices } & \multirow{2}{*}{$\begin{array}{c}\begin{array}{c}\text { Total } \\
\text { citations }\end{array} \\
\mathrm{TC}\end{array}$} \\
\hline & MULTI $_{1}$ & MULTI $_{2}$ & $\mathrm{MULTI}_{3}$ & $\mathrm{SU}_{1}$ & $\mathrm{SU}_{2}$ & $\mathrm{SU}_{3}$ & \\
\hline Hirschmax & $\begin{array}{c}\mathbf{0 . 0 6 5 6} * * * \\
(0.0125)\end{array}$ & $\begin{array}{c}\mathbf{0 . 0 3 7 6 * *} \\
(0.0151)\end{array}$ & $\begin{array}{l}1.1398 * * \\
(0.4633)\end{array}$ & $\begin{array}{l}\text { 0.0607* } \\
(0.0332)\end{array}$ & $\begin{array}{c}\mathbf{0 . 0 8 2 6} * * \\
(0.0360)\end{array}$ & $\begin{array}{c}\mathbf{0 . 1 0 4 6} * * * \\
(0.0353)\end{array}$ & $\begin{array}{c}\mathbf{0 . 8 9 1 2} * * \\
(0.3740)\end{array}$ \\
\hline Pages & $\begin{array}{c}0.0098 \\
(0.0144)\end{array}$ & $\begin{array}{c}0.0277 \\
(0.0174)\end{array}$ & $\begin{array}{c}0.8443 \\
(0.5315)\end{array}$ & $\begin{array}{c}-0.0198 \\
(0.0421)\end{array}$ & $\begin{array}{c}0.0509 \\
(0.0434)\end{array}$ & $\begin{array}{c}\mathbf{0 . 0 8 8 3} * * \\
(0.0427)\end{array}$ & $\begin{array}{c}0.6714 \\
(0.4291)\end{array}$ \\
\hline Female & $\begin{array}{c}0.0736 \\
(0.0764)\end{array}$ & $\begin{array}{c}\mathbf{0 . 1 9 5 7 * *} \\
(0.0926)\end{array}$ & $\begin{array}{l}\mathbf{5 . 9 3 7 9}^{* * *} \\
(2.8314)\end{array}$ & $\begin{array}{c}\mathbf{0 . 4 4 0 5} * * \\
(0.2037)\end{array}$ & $\begin{array}{c}0.3240 \\
(0.2299)\end{array}$ & $\begin{array}{c}\mathbf{0 . 5 4 6 2} * * \\
(0.2172)\end{array}$ & $\begin{array}{c}4.6537 * * \\
(2.2860)\end{array}$ \\
\hline Keynr & $\begin{array}{c}0.0287 \\
(0.0213)\end{array}$ & $\begin{array}{c}\mathbf{0 . 1 3 8 2} * * * \\
(0.0258)\end{array}$ & $\begin{array}{c}4.2574 * * * \\
(0.7888)\end{array}$ & $\begin{array}{l}\text { 0.0964* } \\
(0.0580)\end{array}$ & $\begin{array}{c}\mathbf{0 . 2 1 8 0} * * * \\
(0.0616)\end{array}$ & $\begin{array}{c}\mathbf{0 . 2 1 1 8}^{* * *} \\
(0.0601)\end{array}$ & $\begin{array}{c}\mathbf{3 . 5 0 1 4} * * * \\
(0.6369)\end{array}$ \\
\hline Web & $\begin{array}{c}0.0379 \\
(0.1725)\end{array}$ & $\begin{array}{c}0.0177 \\
(0.2090)\end{array}$ & $\begin{array}{c}0.5245 \\
(6.3948)\end{array}$ & $\begin{array}{c}0.3941 \\
(0.4594)\end{array}$ & $\begin{array}{c}\mathbf{0 . 9 4 0 1 * *} \\
(0.4629)\end{array}$ & $\begin{array}{c}\mathbf{0 . 9 5 0 7 * *} \\
(0.4690)\end{array}$ & $\begin{array}{c}0.3773 \\
(5.1632)\end{array}$ \\
\hline Retrieval & $\begin{array}{l}\mathbf{- 0 . 2 5 4 8 *} \\
(0.1531)\end{array}$ & $\begin{array}{l}\mathbf{- 0 . 3 6 5 0 *} \\
(0.1855)\end{array}$ & $\begin{array}{c}\mathbf{- 1 1 . 1 8 1 4} \\
(5.6747)\end{array}$ & $\begin{array}{l}\mathbf{- 0 . 8 4 4 6 *} \\
(0.4447)\end{array}$ & $\begin{array}{l}-0.4466 \\
(0.4492)\end{array}$ & $\begin{array}{l}-0.3927 \\
(0.4409)\end{array}$ & $\begin{array}{c}\mathbf{- 9 . 0 3 5 8 *} \\
(4.5817)\end{array}$ \\
\hline Y2002 & $\begin{array}{l}0.01557 \\
(0.1198)\end{array}$ & $\begin{array}{c}0.0857 \\
(0.1450)\end{array}$ & $\begin{array}{c}3.9913 \\
(4.4357)\end{array}$ & $\begin{array}{c}\mathbf{0 . 9 0 3 0} * * * \\
(0.3412)\end{array}$ & $\begin{array}{c}\mathbf{1 . 0 6 3 2} * * * \\
(0.3945)\end{array}$ & $\begin{array}{c}0.4829 \\
(0.3675)\end{array}$ & $\begin{array}{l}6.5797^{*} \\
(3.5814)\end{array}$ \\
\hline Tec & $\begin{array}{c}\mathbf{0 . 4 0 1 6} * * * \\
(0.1511)\end{array}$ & $\begin{array}{c}\mathbf{0 . 4 1 8 5 * *} \\
(0.1831)\end{array}$ & $\begin{array}{c}12.7473 * * \\
(5.6012)\end{array}$ & $\begin{array}{c}1.0767 * * * \\
(0.4136)\end{array}$ & $\begin{array}{l}\text { 0.8524* } \\
(0.4609)\end{array}$ & $\begin{array}{c}\mathbf{0 . 9 9 9 4 * *} \\
(0.4495)\end{array}$ & $\begin{array}{c}10.1159 * * \\
(4.5224)\end{array}$ \\
\hline Dauthors & $\begin{array}{l}-0.1554 \\
(0.1346)\end{array}$ & $\begin{array}{l}-0.1589 \\
(0.1630)\end{array}$ & $\begin{array}{l}-4.7853 \\
(4.9875)\end{array}$ & $\begin{array}{l}-0.0808 \\
(0.3817)\end{array}$ & $\begin{array}{l}-0.2102 \\
(0.4229)\end{array}$ & $\begin{array}{l}-\mathbf{- 0 . 7 1 1 9 *} \\
(0.4159)\end{array}$ & $\begin{array}{l}-3.6635 \\
(4.0269)\end{array}$ \\
\hline constant & $\begin{array}{c}0.1667 \\
(0.2014) \\
\end{array}$ & $\begin{array}{l}-0.0734 \\
(0.2416) \\
\end{array}$ & $\begin{array}{c}-2.8463 \\
(7.3900) \\
\end{array}$ & $\begin{array}{c}-2.1061 \\
(0.5981) \\
\end{array}$ & $\begin{array}{r}-3.9657 \\
(0.7764) \\
\end{array}$ & $\begin{array}{l}-3.7294 \\
(0.7112) \\
\end{array}$ & $\begin{array}{l}-3.7658 \\
(5.9666) \\
\end{array}$ \\
\hline Adj. $R^{2}$ & 0.1460 & 0.2087 & 0.2102 & & & & 0.2169 \\
\hline
\end{tabular}




\begin{tabular}{|c|c|c|c|c|c|c|c|}
\hline $\begin{array}{l}\text { Pseudo } \mathrm{R}^{2} \\
\text { \# obs. } \\
\text { Prob.>F } \\
\text { Prob. }>\text { chi }^{2}\end{array}$ & $\begin{array}{c}201 \\
0.0000\end{array}$ & $\begin{array}{c}202 \\
0.0000\end{array}$ & $\begin{array}{c}202 \\
0.0000\end{array}$ & $\begin{array}{c}0.1147 \\
202 \\
\cdot \\
0.0006\end{array}$ & $\begin{array}{c}0.1886 \\
202 \\
. \\
0.0000\end{array}$ & $\begin{array}{c}0.2142 \\
202 \\
. \\
0.0000\end{array}$ & $\begin{array}{c}202 \\
0.0000\end{array}$ \\
\hline
\end{tabular}

Estimated coefficient (standard error)

*: significant at 10\% level; **: significant at 5\% level; ***: significant at $1 \%$ level

\section{$\underline{\text { Figures }}$}

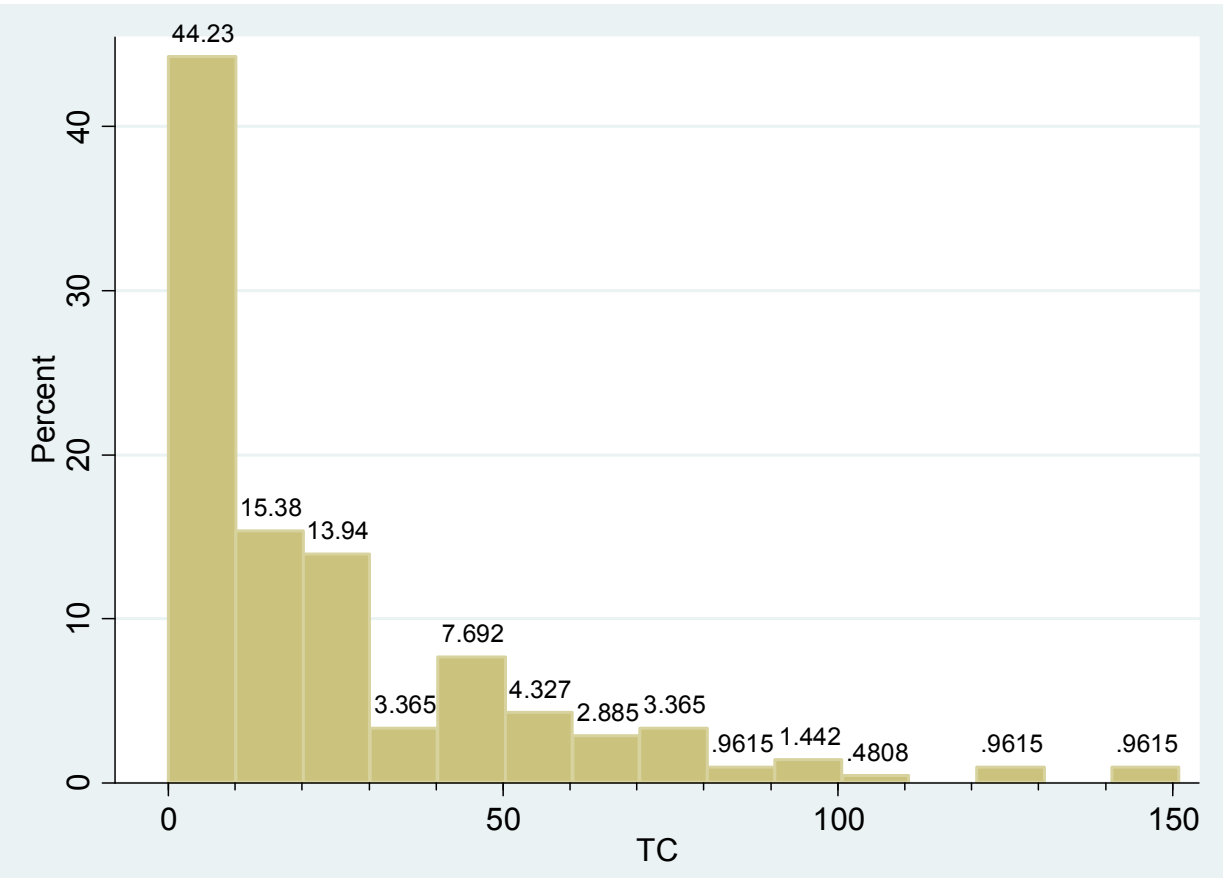

Figure 1: Citation frequency distribution of articles published in JASIST (2002-2003); data collected in June 2014. TC stands for total number of citations. 


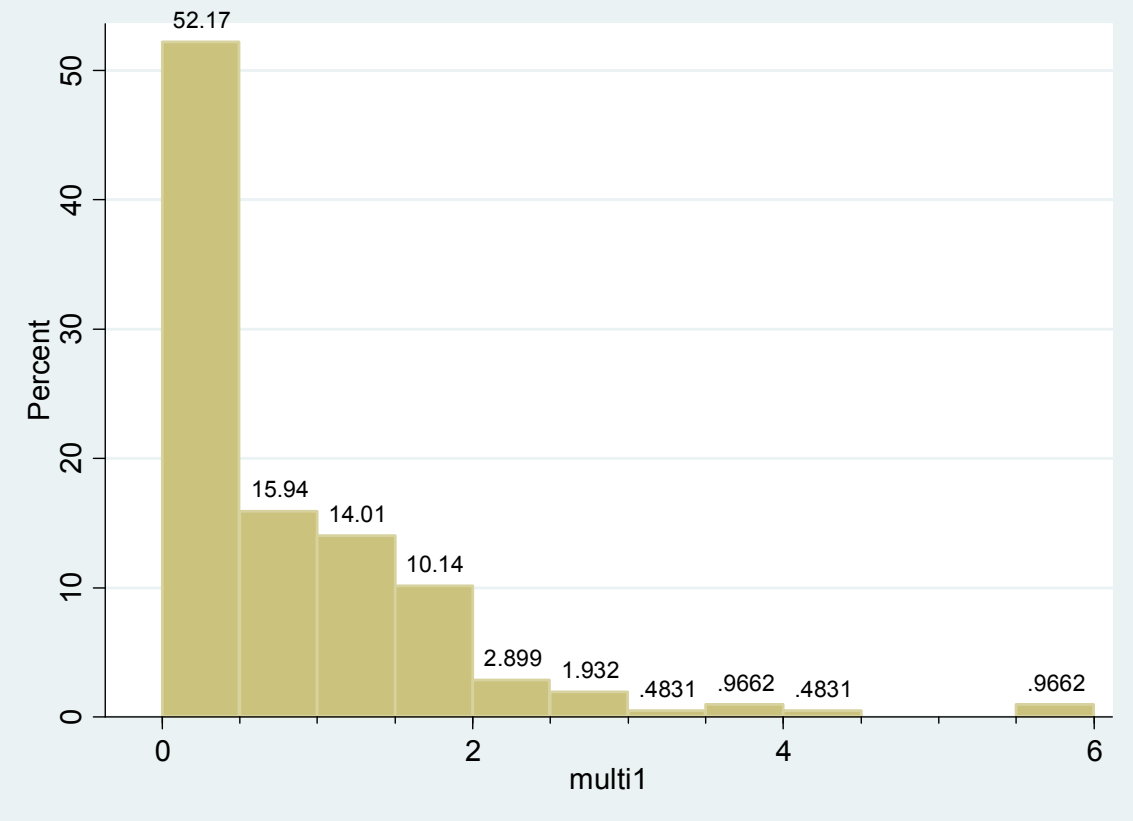

Figure 2: Distribution of MULTI

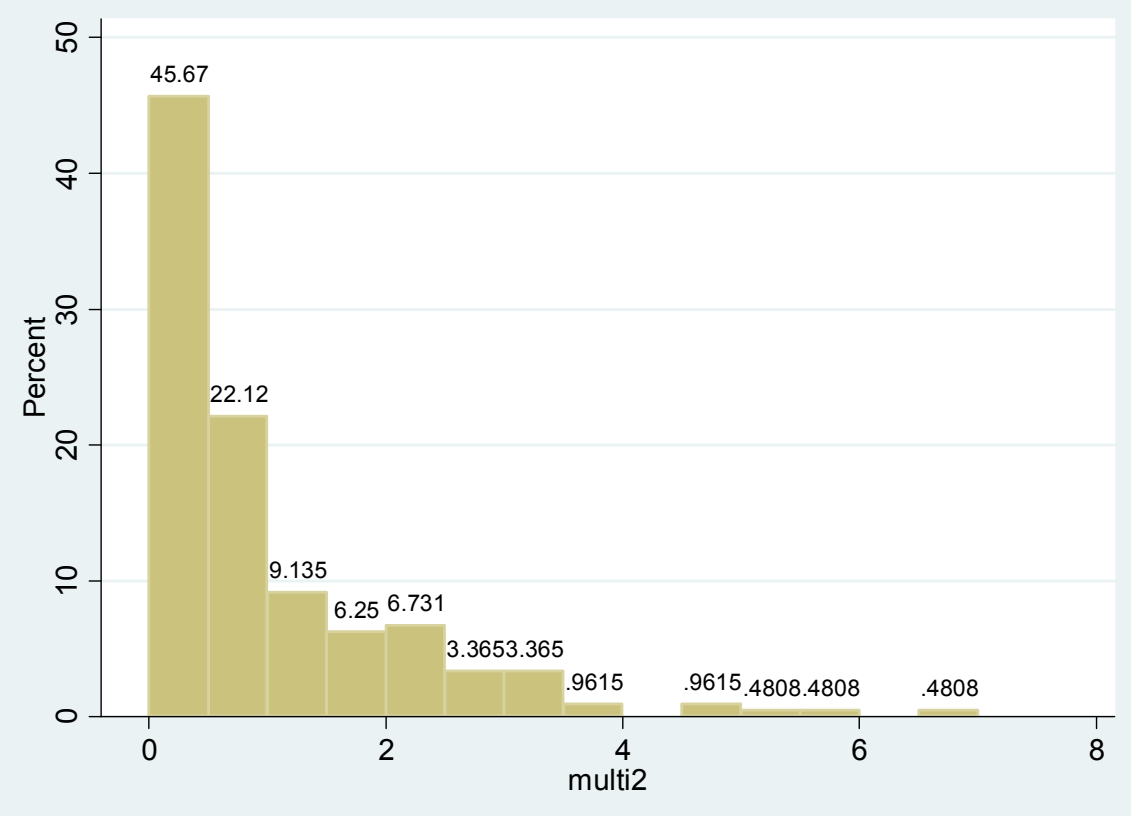

Figure 3: Distribution of MULTI 


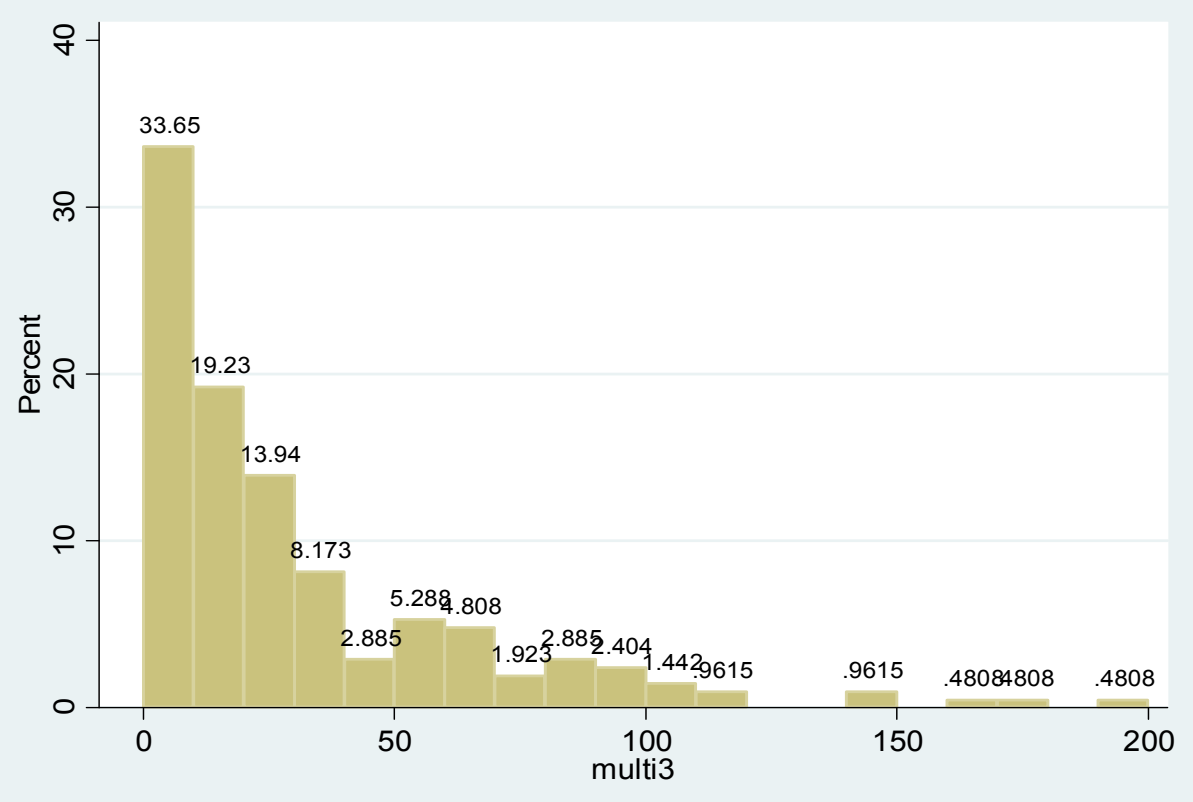

Figure 4: Distribution of $\mathrm{MULTI}_{3}$ 